\title{
Probing membrane protein orientation and structure using fast magic-angle-spinning solid-state NMR
}

\author{
O.C. Andronesi ${ }^{\mathrm{a}}$, J.R. Pfeifer ${ }^{\mathrm{b}}$, L. Al-Momani ${ }^{\mathrm{b}}$, S. Özdirekcan ${ }^{\mathrm{c}}$, D.T.S. Rijkers ${ }^{\mathrm{d}}$,

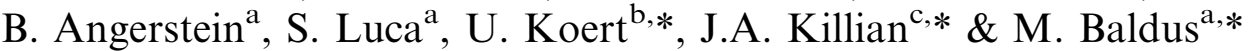 \\ ${ }^{a}$ Max-Planck-Institute for Biophysical Chemistry, Department of NMR-Based Structural Biology, Am \\ Fassberg 11, 37077 Göttingen, Germany; 'bachbereich Chemie, Philipps-Universität Marburg, Hans- \\ Meerwein-Strasse, 35032 Marburg, Germany; ${ }^{\mathrm{c}}$ Department of Biochemistry of Membranes, Utrecht Uni- \\ versity, Padualaan 8, $3584 \mathrm{CH}$ Utrecht, The Netherlands; ${ }^{\mathrm{d}}$ Department of Medicinal Chemistry, Utrecht \\ Institute for Pharmaceutical Sciences, Faculty of Pharmacy, Utrecht University, Sorbonnelaan 16, 3584 \\ CA Utrecht, The Netherlands
}

Received 19 April 2004; Accepted 2 September 2004

Key words: MAS, membrane proteins, NMR, solid-state, structure determination

Abbreviations: ssNMR - solid state NMR; MAS - Magic Angle Spinning; R.F. - Radio Frequency; CSA - Chemical Shift Anisotropy; CP - Cross Polarization; APHH-CP - Adiabatic-Passage Hartmann-Hahn Cross-Polarization; SPECIFIC-CP - Spectrally Induced Filtering In Combination with Cross-Polarization; TPPM - Two Pulse Phase Modulation; TPPI - Time Proportional Phase Incrementation; DQ - Double Quantum; SQ - Single Quantum; POST-C7 - Permutationally Offset Stabilized C7; SPC-5 - Supercycled POST-C5; SD - Spin Diffusion; AHT - Average Hamiltonian Theory; TFE - Trifluoroethanol; $\quad$ DMPC - 1,2-Dimyristoyl-sn-glycero-3-Phosphocholine; $\quad$ WALP23 - Trpflanked poly(alanine-leucine) peptides; PEEK - Polyetheretherketone; PTFE - Polytetrafluoroethylene; Fmoc - 9-Fluorenylmethoxycarbonyl.

\begin{abstract}
One and two-dimensional solid-state NMR experiments are discussed that permit probing local structure and overall molecular conformation of membrane-embedded polypeptides under Magic Angle Spinning. The functional dependence of a series of anisotropic recoupling schemes is analyzed using theoretical and numerical methods. These studies lead to the construction of a set of polarization dephasing or transfer units that probe local backbone conformation and overall molecular orientation within the same NMR experiment. Experimental results are shown for a randomly oriented peptide and for two model membrane-peptides reconstituted into lipid bilayers and oriented on polymer films according to a method proposed by Bechinger et al. [J. Am. Chem. Soc., 124, (2002), 1146-1147].
\end{abstract}

\section{Introduction}

Determining the three-dimensional structures of membrane peptides and proteins at atomic resolution is fundamental to the understanding of

*To whom correspondence should be addressed: E-mails: koert@chemie.uni-marburg.de,j.a.killian@chem.uu.nl,maba@ mpibpc.mpg.de many important biological functions including receptor activation or ion conductivity. Moreover, the structural study of membrane embedded peptides may reveal novel insights into the details of membrane fusion and transport. In addition to X-ray and neutron scattering techniques (Salditt, 2003), solid-state Nuclear Magnetic Resonance (NMR) has long been utilized to examine membrane protein structure at 
atomic resolution. In particular, investigations using static, macroscopically oriented samples have become an invaluable tool for the study of peptides and proteins interacting with phospholipid bilayers (Cross and Opella, 1994; Marassi and Opella, 1998; Bechinger et al., 1999). As of to date, such approaches have lead to several 3D structures of membrane-interacting peptides including Gramicidin A (Ketchem et al., 1993) or, most recently, the coat protein in fd filamentous bacteriophage particles (Zeri et al., 2003).

On the other hand, Magic-Angle-Spinning (MAS (Andrew et al., 1958)) solid-state NMR has successfully been used to probe structural aspects in membrane proteins for a long time (McDowell and Schaefer, 1996; Smith et al., 1996; Griffin, 1998; Thompson, 2002; Luca et al., 2003a). For example, MAS-based solid-state NMR methods have been employed to probe individual structural parameters such as the local backbone conformation (Smith et al., 2001a; Gabrys et al., 2003) and monomer-monomer contacts (Fu et al., 2000; Smith et al., 2001b; Yang and Weliky, 2003) in membrane-embedded peptides or the entire backbone conformation of a uniformly labeled peptide ligand bound to its G-protein coupled receptor (Luca et al., 2003b). In addition to the detection of local structural aspects, MAS-based methods are available to probe the overall orientation of the peptide in the membrane, for example by employing heteronuclear dipolar recoupling experiments under MAS (Hirsh et al., 1996). Alternatively, experiments that combine MAS and macroscopic sample orientation have given additional insight into molecular structure ranging from oriented polymers (Opella and Waugh, 1977; Harbison and Spiess, 1986) to protein fibers (Demura et al., 1998). Since model lipid membranes are well known to orient on solid supports under appropriate experimental conditions, this concept could be extended for the structural study of membrane peptides and proteins (Glaubitz and Watts, 1998; Sizun and Bechinger, 2002). Here, ${ }^{15} \mathrm{~N}$ or ${ }^{2} \mathrm{H}$ NMR spectroscopy on isotope-labeled peptides has often been used to probe molecular orientation in a membrane environment. Because of technical limitations or due to the fact that structural parameters have been extracted from a spinning side band analysis of anisotropic interactions (Herzfeld and Berger, 1980; Glaubitz et al., 1999; Grobner et al., 2000), fast MAS and the concomitant gain in spectral resolution and sensitivity could, thus far, not be exploited. Signal to noise considerations are, however, often of critical importance and may represent a strong determinant as to whether solid-state NMR based investigations in membrane proteins in static or MAS-related experiments are feasible. Moreover, polarization transfer schemes that can provide the basis for further structural investigations are most effective at fast MAS rates and ultrahigh magnetic fields where signal overlap due to spinning sidebands and line-width modulations due to unwanted recoupling effects can be minimized. Compared to structural studies using statically aligned samples (Marassi and Opella, 2000; Wang et al., 2000; Mesleh et al., 2003), MAS based methods may offer an increase in sensitivity and better control of experimental parameters such as hydration level and temperature over extended time periods. Moreover, such techniques can be readily employed on conventional MAS probe heads.

These aspects provide a strong incentive to establish a general set of NMR experiments that allows for the extraction of a variety of structural parameters of membrane embedded peptides at the highest achievable MAS rates. In the following, we are particularly interested in incorporating the detection of macroscopic peptide orientation into standard two-dimensional $\left({ }^{13} \mathrm{C}\right.$, ${ }^{15} \mathrm{~N}$ ) assignment methods which may involve polarization transfer methods using throughbond or dipolar through-space interactions (Baldus, 2002). In addition, signal dephasing due to an orientation-dependent chemical shielding interaction can be used to encode molecular orientation in high spectral resolution. Both type of signal modulation schemes are also sensitive to local structural parameters such as backbone conformation or hydrogen-bonding. In the following, we exemplify how standard r.f. recoupling schemes can be combined to probe both type of structural parameters in a standard 1D or 2D NMR experiment.

Experimental results are shown for two types of transmembrane peptides, i.e., Gramicidin A and WALP23. Gramicidin A is a channel-forming antibiotic peptide (Killian, 1992; Cross et al., 1999), while WALP23 represents a member of a family of Trp-flanked peptides designed to mimic $\alpha$-helical trans-membrane segments of intrinsic 
membrane proteins (De Planque and Killian, 2003). Both systems have been well characterized by solid-state NMR using static, macroscopically oriented specimen. While Gramicidin A readily incorporates into phospholipid membranes as a right-handed $\beta^{6.5}$ helix (Ketchem et al., 1993, 1997; Cross et al., 1999), WALP peptides have been shown to adopt an $\alpha$-helical arrangement in model membranes (de Planque et al., 2002; Strandberg et al., 2002, submitted; van der Wel et al., 2002). These peptides were reconstituted into model DMPC bilayers and mechanically oriented onto thin polyetheretherketone (PEEK) films (Auge et al., 1997; Sizun and Bechinger, 2002).

\section{Material and methods}

\section{Materials}

Uniformly $\left[{ }^{13} \mathrm{C},{ }^{15} \mathrm{~N}\right]$ labeled Fmoc alanine and leucine were purchased from Cambridge Isotope Laboratories (CIL, Andover, MA). 1,2-Dimyristoyl-sn-glycero-3-phosphocholine was obtained from Avanti Polar Lipids Inc. (Alabaster, AL) and used without further purification. 2,2,2-Trifluoroethanol (TFE) was obtained from Fluka. Gramicidin A which constitutes the major component of gramicidin is a pentadecameric peptide (HCO-VGALAVV므는 $)_{3} \mathrm{~W}-\mathrm{CONHCH}_{2}-\mathrm{CH}_{2} \mathrm{OH}$, $\mathrm{D}$-amino acids are underlined) and has been prepared by segment coupling in solution as previously described (Arndt et al., 2002). WALP23 (amino acid sequence acetyl-GWW(LA) 8 LWWAamide), labeled at positions 6 and 7, was synthesized on an Applied Biosystems 433A Peptide Synthesizer using the FastMoc protocol on a $0.25 \mathrm{mmol}$ scale until the position of the label was reached. Subsequently, $\left[{ }^{13} \mathrm{C},{ }^{15} \mathrm{~N}\right]$ labeled Fmoc leucine and alanine were coupled, in an excess of only two equivalents, and the remaining amino acid sequence was synthesized manually, as previously described for photolabelled WALP23 (Ridder et al., submitted). PEEK was purchased from Goodfellow/Germany.

\section{Sample preparation}

For the preparation of the Gramicidin NMR sample, $15 \mathrm{mg}$ of DMPC were dissolved in $100 \mu \mathrm{TFE}, 3 \mathrm{mg}$ Gramicidin in $50 \mu \mathrm{l}$ TFE were added, vortexed and evenly distributed on $15 \mathrm{~cm}$ $\times 1 \mathrm{~cm}$ film of PEEK. $3 \mathrm{mg}$ of the WALP23 peptide were dissolved in $200 \mu \mathrm{TFE}$ and dried at $55^{\circ} \mathrm{C}$ in a rotary evaporator. $15 \mathrm{mg}$ of DMPC dissolved in $200 \mu \mathrm{l}$ TFE were added to the peptide film, vortexed and dried again. Samples were dissolved in $150 \mu \mathrm{l}$ TFE and distributed on $15 \mathrm{~cm} \times 1 \mathrm{~cm}$ film of PEEK. After evaporation of the solvent, PEEK layers were kept overnight under high vacuum and hydrated at $\sim 90 \%$ humidity and $45^{\circ} \mathrm{C}$ for 2 days. The films were subsequently rolled, mechanically stabilized using an outer layer of PTFE tape and packed into a $4 \mathrm{~mm}$ rotor. In all cases, the macroscopic sample alignment was checked by a Floquet MAS sideband analysis (Baldus et al., 1994a) of the resulting ${ }^{31} \mathrm{P}$ NMR MAS spectra. Notable, the sample orientation and hydration level in the MAS rotor was repeatedly checked and proved to be stable over the entire time frame of the discussed experiments (3 months).

\section{NMR spectroscopy and data analysis}

All NMR experiments were conducted on wide bore $400 \mathrm{MHz}$ and $600 \mathrm{MHz}$ instruments (Bruker Biospin, Germany) using double-resonance $\left({ }^{1} \mathrm{H},{ }^{31} \mathrm{P}\right)$ and triple-resonance $\left({ }^{1} \mathrm{H},{ }^{13} \mathrm{C},{ }^{15} \mathrm{~N}\right) 4 \mathrm{~mm}$ MAS probe heads. Sample alignment was checked above the gel to liquid-crystalline phase transition, typically around $40{ }^{\circ} \mathrm{C}$ using standard ${ }^{31} \mathrm{P}$ spectroscopy. All other $\left({ }^{13} \mathrm{C},{ }^{15} \mathrm{~N}\right) \mathrm{NMR}$ experiments were subsequently performed around $-15{ }^{\circ} \mathrm{C}$ to minimize signal loss during cross polarization due to mobility effects and to allow for faster MAS rates. As shown in the Supplementary material $\mathrm{A}$, increasing the MAS rate from 1.2 to $6 \mathrm{kHz}$ leads, for example, to a significant increase in signal to noise ratio in ${ }^{15} \mathrm{~N}$ experiments on oriented Gramicidin A. All samples were fast-frozen by plunging the rotor in a liquid solution at $-15{ }^{\circ} \mathrm{C}$ prepared by mixing 3-1 $(\mathrm{w} / \mathrm{w})$ ice with $\mathrm{NaCl}$ and subsequently inserted in a pre-cooled MAS probehead at $-15^{\circ} \mathrm{C}$. Similar techniques have been used extensively in solidstate NMR studies of membrane peptides under static (Hu et al., 1995; Tian and Cross, 1998; Cross and Quine, 2000) and MAS conditions (Glaubitz et al., 1999; Glaubitz et al., 2000; Sizun and Bechinger, 2002; Bodner et al., 2004). ${ }^{31} \mathrm{P}$ NMR spectra recorded after low-temperature 

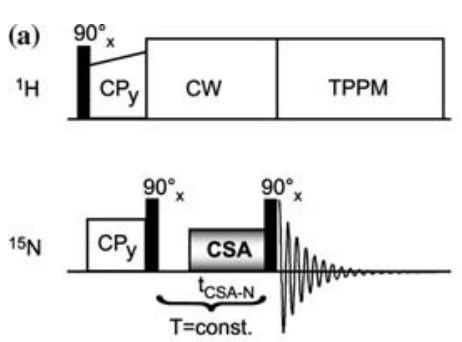

(b)
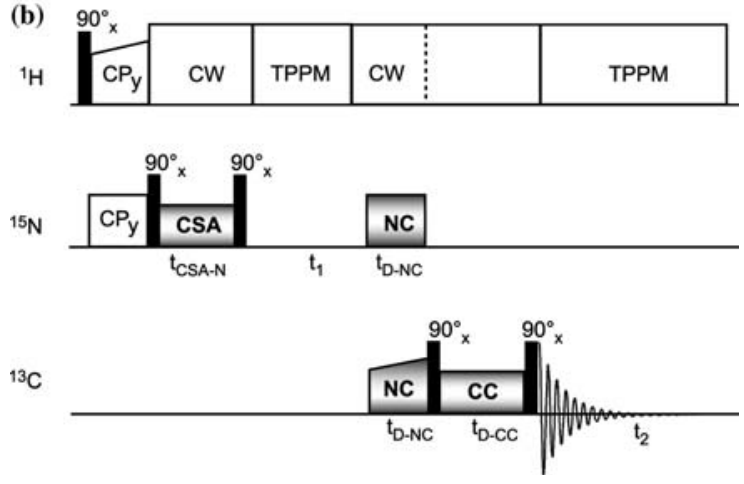

Figure 1. One - and two-dimensional NMR pulse schemes to read out anisotropic interactions under MAS conditions. During free evolution and detection periods, TPPM proton decoupling (Bennett et al., 1995) was employed. Anisotropic chemical shielding interactions (CSA) were recoupled using a set of radio frequency (r.f.) schemes introduced by Levitt and coworkers (Levitt, 2002). These, so called, R $18^{7}{ }_{1}$ and $\mathrm{R} 18^{5}{ }_{2}$ schemes involve $(\pi \bar{\pi})_{\phi}$ phase switches with phases $\phi=70^{\circ}$ and $\phi=50^{\circ}$ over one or two rotor periods, respectively (Carravetta et al., 2000; Zhao et al., 2001) and were conducted in a constant-time fashion. Heteronuclear transfer (NC) was accomplished under APHH-CP (Baldus et al., 1996) or SPECIFIC CP (Baldus et al., 1998) conditions. Homonuclear $\left({ }^{13} \mathrm{C},{ }^{13} \mathrm{C}\right)$ mixing $(\mathrm{C}, \mathrm{C})$ involved proton-driven spin diffusion (SD) (Bloembergen, 1949), POST-C7 (Hohwy et al., 1998) and SPC5 (Hohwy et al., 1999) double-quantum recoupling. At high MAS rates, proton decoupling during DQ mixing may be removed and tailored sequences may be employed (Hughes et al., 2004).

NMR runs indicated that all samples were stable under the considered experimental conditions. In general, MAS rates in the range of $5-6 \mathrm{kHz}$ were used.

One and two-dimensional NMR pulse schemes to read out anisotropic interactions under MAS conditions are depicted in Figure 1. During free evolution and detection periods, TPPM proton decoupling (Bennett et al., 1995) was employed. Anisotropic chemical shielding interactions (CSA) were recoupled using a set of radio frequency (r.f.) schemes introduced by Levitt and coworkers (Levitt, 2002). These, so called, $\mathrm{R} 18^{7}{ }_{1}$ and $\mathrm{R} 18^{5}{ }_{2}$ schemes involve multiple $(\pi \bar{\pi})_{\phi}$ phase switches with phases $\phi=70^{\circ}$ and $\phi$ $=50^{\circ}$, respectively (Carravetta et al., 2000; Zhao et al., 2001) and were, in the context of our experiments, conducted in a constant-time fashion. Heteronuclear transfer was accomplished using adiabatic passage APHH-CP (Baldus et al., 1996) or SPECIFIC CP (Baldus et al., 1998) transfers. Homonuclear $\left({ }^{13} \mathrm{C},{ }^{13} \mathrm{C}\right)$ mixing involved proton-driven spin diffusion (SD) (Bloembergen, 1949) or POST-C7 (Hohwy et al., 1998) and SPC5 (Hohwy et al., 1999) doublequantum recoupling. The $2 \mathrm{D}\left({ }^{13} \mathrm{C},{ }^{15} \mathrm{~N}\right)$ implementation shown in Figure $1 \mathrm{~b}$ includes standard TPPI phase cycling (Ernst et al., 1987) to insure phase-sensitive detection. Data processing involved the use of MATLAB (The Mathworks Inc., Natick, MA) and MatNMR (http:// matnmr.sourceforge.net). For both considered peptides, experimentally determined secondary chemical shifts were calculated according to Luca et al., (2001).

The experimental results were compared to numerical simulations within the $\mathrm{C}++$ based simulation environment GAMMA (Smith et al., 1994). The explicit time dependence of the system Hamiltonian due to the combined effect of MAS and the considered r.f. pulse schemes was described using a Floquet analysis (Baldus et al., 1994a; Levante et al., 1995) or piece-constant Hamiltonian (see, for example, Baldus (2002)). Size and PAS orientation of the anisotropic chemical shielding interactions were taken from the literature, as will be indicated. In the case of WALP23, ${ }^{13} \mathrm{C}$ resonance assignments were also used to predict the backbone dihedral angles $\psi$ and $\phi$ using the TALOS (Cornilescu et al., 1999) package.

\section{Theory}

Average Hamiltonian theory (Haeberlen, 1976) has previously been used to describe the effect of the CSA and dipolar recoupling under MAS for the case of a randomly oriented sample. Using spherical tensor notation, the spin tensor components and rank 0 space tensor elements (such as the isotropic chemical shift) remain unchanged if one considers the problem of a macroscopically oriented system subjected to MAS. The functional 
dependence of the higher rank space tensor elements on the molecular orientation can be obtained from a succession of four Euler transformations (Brink and Satchler, 1961) between five different reference frames:

$$
\begin{aligned}
& P A S \stackrel{(\alpha, \beta, 0)}{\longrightarrow} M O L, \\
& M O L \stackrel{(\varphi, \theta, 0)}{\longrightarrow} M E M, \\
& M E M \stackrel{\left(\varphi_{R}, \theta_{R}, 0\right)}{\longrightarrow} R A S, \\
& R A S \stackrel{\left(\omega_{R} t, \theta_{M A S}, 0\right)}{\longrightarrow} L A B .
\end{aligned}
$$

In the principal axis system (PAS), the anisotropic interaction $\Lambda$ of interest depends on the anisotropy $\delta_{\Lambda}$ and the asymmetry $\eta_{\Lambda}$ and can be represented by the following set of rank 2 spherical space tensor components (Mehring, 1983):

$$
\begin{aligned}
& A_{20}^{P A S, \Lambda}=\sqrt{3 / 2} \delta_{\Lambda}, \\
& A_{2 \pm 2}^{P A S, \Lambda}=1 / 2 \delta_{\Lambda} \eta_{\Lambda} .
\end{aligned}
$$

For a general definition of the spherical tensor elements, see for example, Mehring (1983) and Baldus (2002). In the present context, $\Lambda$ refers to the anisotropic ${ }^{15} \mathrm{NH}$ chemical shielding (CSA) and the dipolar $\left({ }^{15} \mathrm{NH}-{ }^{13} \mathrm{C} \alpha\right)$ and $\left({ }^{13} \mathrm{C} \alpha-{ }^{13} \mathrm{C} \beta\right)$ interactions. NMR pulse schemes making use of the (one-bond) dipolar $\left({ }^{1} \mathrm{H},{ }^{15} \mathrm{~N}\right)$ interaction could also be designed but will not be considered in the context of this contribution.

Figure 2 summarizes the relationship between the laboratory frame (LAB, $\mathrm{Z}$ axis along the static magnetic field), the rotor axis system (RAS, Z axis along the rotor axis), the membrane frame (MEM, Z axis along the membrane normal $\vec{n}$, also known as the sample director frame), the molecular frame (MOL, $\mathrm{Z}$ axis along molecule symmetry axis $\vec{a}$ ), and the principal axis system (characterized by the PAS values and the angles $\beta_{\Lambda}$ for each interaction, or shortly $\beta$ as in Equation 1). For example, $\beta_{\mathrm{CSA}-\mathrm{N}}, \beta_{\mathrm{D}-\mathrm{NH}}, \beta_{\mathrm{D}-\mathrm{NC} \alpha}$, and $\beta_{\mathrm{D}-\mathrm{C} \alpha \mathrm{C} \beta}$ are shown in Figure 2. The $Z$ axis $\vec{a}$ of the MOL frame can be chosen to coincide with the molecular symmetry axis, for example in the case of an $\alpha$-helix (WALP23) or $\beta$-helix (Gramicidin A). In explicit form, the corresponding rank-2 spherical tensor components are obtained using the standard set of reduced Wigner elements of rank 2 :

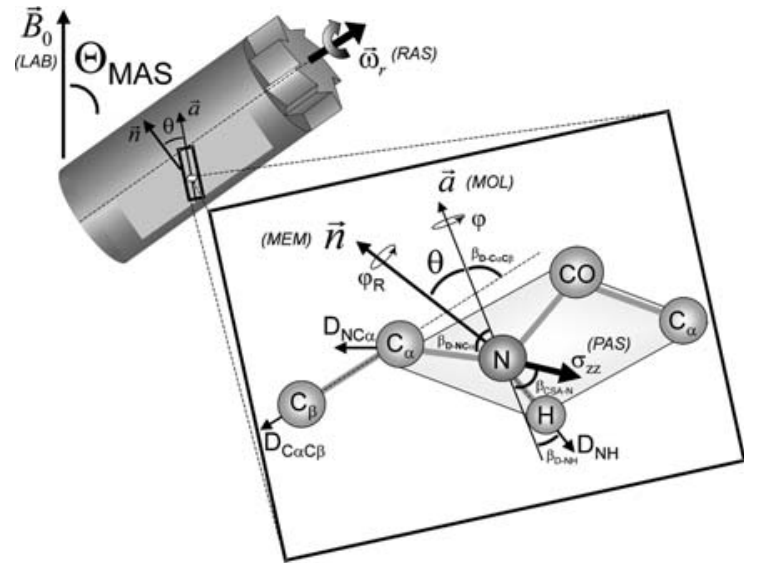

Figure 2. Molecular geometry relevant in the context of MAS of membrane bilayers oriented onto PEEK films: The tilt angle $\theta$ relates the membrane normal $\vec{n}$ to the molecule reference axis $\vec{a}$. The angle $\beta_{\Lambda}$ connects the molecular axis $\vec{a}$, and the $\mathrm{z}$ axis of PAS (principal axis system) of each considered interaction $\Lambda$. Finally, the azimuthal angles $\varphi_{\mathrm{R}}$ and $\varphi$ corresponding to z-rotations around $\vec{n}$ and $\vec{a}$, respectively, are displayed. For the sake of clarity, additional Euler angles relevant for the theoretical analysis (see Equation 1) are not shown.

$$
\begin{aligned}
& A_{2 M}^{R A S, \Lambda}=\sum_{m^{\prime}=-2}^{2} A_{2 m^{\prime}}^{M E M} \exp \left[-i m^{\prime} \varphi_{R}\right] d_{m^{\prime} M}\left(\theta_{R}\right), \\
& A_{2 n}^{M E M, \Lambda}=\sum_{n^{\prime}=-2}^{2} A_{2 n^{\prime}}^{M O L, \Lambda} \exp \left[-i n^{\prime} \varphi\right] d_{n^{\prime} n}(\theta), \\
& A_{2 l}^{M O L, \Lambda}=\sum_{l^{\prime}=-2}^{2} A_{2 l^{\prime}}^{P A S, \Lambda} \exp \left[-i l^{\prime} \alpha\right] d_{l^{\prime} l}\left(\beta_{\Lambda}\right) .
\end{aligned}
$$

From Equation 3, the general expression for the relevant space components in the RAS frame can be calculated:

$$
\begin{aligned}
A_{2 M}^{R A S, \Lambda}= & \sum_{m^{\prime}, n^{\prime}, l^{\prime}=-2}^{2} d_{m^{\prime} M}\left(\theta_{R}\right) d_{n^{\prime} m^{\prime}}(\theta) d_{l^{\prime} n^{\prime}}\left(\beta_{\Lambda}\right) A_{2 l^{\prime}}^{P A S, \Lambda} \\
& \times \exp \left[(-i)\left(m^{\prime} \varphi_{R}+n^{\prime} \varphi+l^{\prime} \alpha\right)\right],
\end{aligned}
$$

where $M$ represents the possible space tensor components recoupled by the r.f. scheme, i.e., $M= \pm 1$ or $M= \pm 2$. In general, the angle $\beta_{\Lambda}$ is fixed by the molecular structure and has been investigated in a variety of model compounds. In the case of an $\alpha$-helix, where the ${ }^{15} \mathrm{~N}-{ }^{1} \mathrm{H}$ dipolar vector approximately coincides with the helix axis, $\beta_{\mathrm{CSA}-\mathrm{N}}$ angles of $\left(15^{\circ}-20^{\circ}\right)$ are usually found (Marassi, 2002). For $\beta$-helices (such as in the case of Gramicidin A) the ${ }^{15} \mathrm{~N}-{ }^{1} \mathrm{H}$ bonds are no longer oriented parallel to the molecular $Z$ axis (see 
Figure 2) and the PAS orientation in the peptide plane frame (Mai et al., 1993) does not coincide with the PAS orientation relative to the MOL frame. For symmetric tensors $\left(A_{22}^{P A S, \Lambda}=0\right)$ such as found for the dipolar coupling or for ${ }^{15} \mathrm{NH}$ CSA tensors with very small asymmetry parameters, the NMR measurements are unaffected by the angle $\alpha$ (see Supplementary material B for further details). In the case of cylindrical symmetry around the membrane normal, the signal modulation is hence determined by the tilt angle $\theta$ between molecular and membrane frame directors $\vec{a}$ and $\vec{n}$, respectively, and the (azimuthal) angle $\varphi$, that defines a rotation around the molecular frame director $\vec{a}$. If PAS and MOL frame coincide $\left(\beta=0^{\circ}\right)$, Equation 4 reduces to:

$$
A_{2 M}^{R A S, \Lambda}=\delta_{\Lambda} \sqrt{\frac{3}{2}} \sum_{m^{\prime}=-2}^{2} d_{m^{\prime} M}\left(\theta_{R}\right) d_{0 m^{\prime}}(\theta) \exp \left[-i m^{\prime} \varphi_{R}\right] .
$$

The angle $\theta_{R}$ describes the orientation of the membrane normal relative to the rotor fixed axis system. Watts and co-workers (Glaubitz and Watts, 1998; Glaubitz et al., 1999) have proposed a macroscopic alignment using glass plates where $\theta_{R}=0$. In this case, Equation 5 can be further simplified to:

$$
A_{2 M}^{R A S, \Lambda}=\frac{3}{4} \delta_{\Lambda} \begin{cases}\sin (2 \theta) \exp \left[\mp i \varphi_{R}\right], & \mathrm{M}= \pm 1 \\ \sin ^{2}(\theta) \exp \left[\mp 2 i \varphi_{R}\right], & \mathrm{M}= \pm 2 .\end{cases}
$$

indicating a simple geometrical dependence of the anisotropic recoupling element on the tilt angle (Glaubitz et al., 2001). Note that for $\theta=0^{\circ}$, i.e., a trans-membrane orientation, the recoupling element vanishes for both conditions. For the case considered in our contribution, where lipid bilayers are oriented onto a cylinder wrapped from thin PEEK (Sizun and Bechinger, 2002) $\left(\theta_{R}=90^{\circ}\right)$, Equation 5 can be evaluated to:

$$
A_{2 M}^{R A S, \Lambda}=\frac{3}{4} \delta_{\Lambda}\left\{\begin{array}{c}
\sin (2 \theta) \cos \left(\varphi_{R}\right) \\
\pm i \sin ^{2}(\theta) \sin \left(2 \varphi_{R}\right) \\
M= \pm 1 \\
\frac{1}{2}\left\{\sin ^{2}(\theta) \cos \left(\varphi_{R}\right)+3 \cos ^{2}(\theta)\right. \\
\left.-1 \mp 2 i \sin (2 \theta) \sin \left(\varphi_{R}\right)\right\} \\
M= \pm 2
\end{array}\right.
$$

Here, the $M= \pm 2$ condition predicts a signal modulation also in the trans-membrane case.
As discussed in further detail in the supplementary material $\mathrm{B}$, an analytical description of the signal intensity can be obtained by constructing the zeroth order average Hamiltonian (Haeberlen, 1976) $H_{M}^{(0), \Lambda}$ from Equation 4 for a given interaction $\Lambda$ and space state number $M$. For the case of equations. 5-7, the analytical result fully agrees with a numerical study, employing a piece-wise constant Hamiltonian. For the general case discussed in the following (Equations 3-4), quantum-mechanical simulations were performed using the GAMMA software to elucidate the signal modulation under the r.f. schemes discussed in Figure 1. In particular, we

(a) Study the dependence of the signal evolution as a function of the tilt angle $\theta$ for different values $\beta_{\Lambda}(\Lambda=$ CSA-N, D-NC and D-CC).

(b) Elucidate the influence of $\varphi$ upon the signal intensity.

(c) Compare the theoretical results to experimental data.

The angular distribution around an average molecular tilt angle $\theta$ (also called mosaicity) was approximated by a Gaussian distribution $g(\theta, \Delta)$ in all numerical studies. The standard deviation $\Delta$ was determined experimentally from a ${ }^{31} \mathrm{P}$ spinning sideband analysis (see supplementary material C). The validity of our numerical approach was also confirmed by calculation of the ${ }^{15} \mathrm{~N}$ spinning sideband pattern obtained from a CP MAS experiment on an oriented sample of Gramicidin A (see Supplementary material C).

\section{Results and discussion}

\section{Numerical predictions}

In Figure 3, numerical predictions of the signal modulations due to CSA, dipolar NC or dipolar $\mathrm{CC}$ interactions are shown. In all cases, the signal was computed as a function of the molecular tilt angle $\theta$ ranging from $0^{\circ}$ to $90^{\circ}$ in steps of $10^{\circ}$, for one (CSA) or two (NC,CC) distinct values of $\beta_{\Lambda}$. In general, we consider the molecular geometry relevant for an ideal $\alpha$-helix with the $\vec{a}$ axis of MOL frame along the ${ }^{15} \mathrm{~N}-{ }^{1} \mathrm{H}$ bonds, i.e., $\beta_{\mathrm{CSA}-}$ $\mathrm{N}=17^{\circ}$. PAS values of the ${ }^{15} \mathrm{~N}$ CSA tensor were taken from the literature (Sizun and Bechinger, 2002). In addition, results are displayed for 

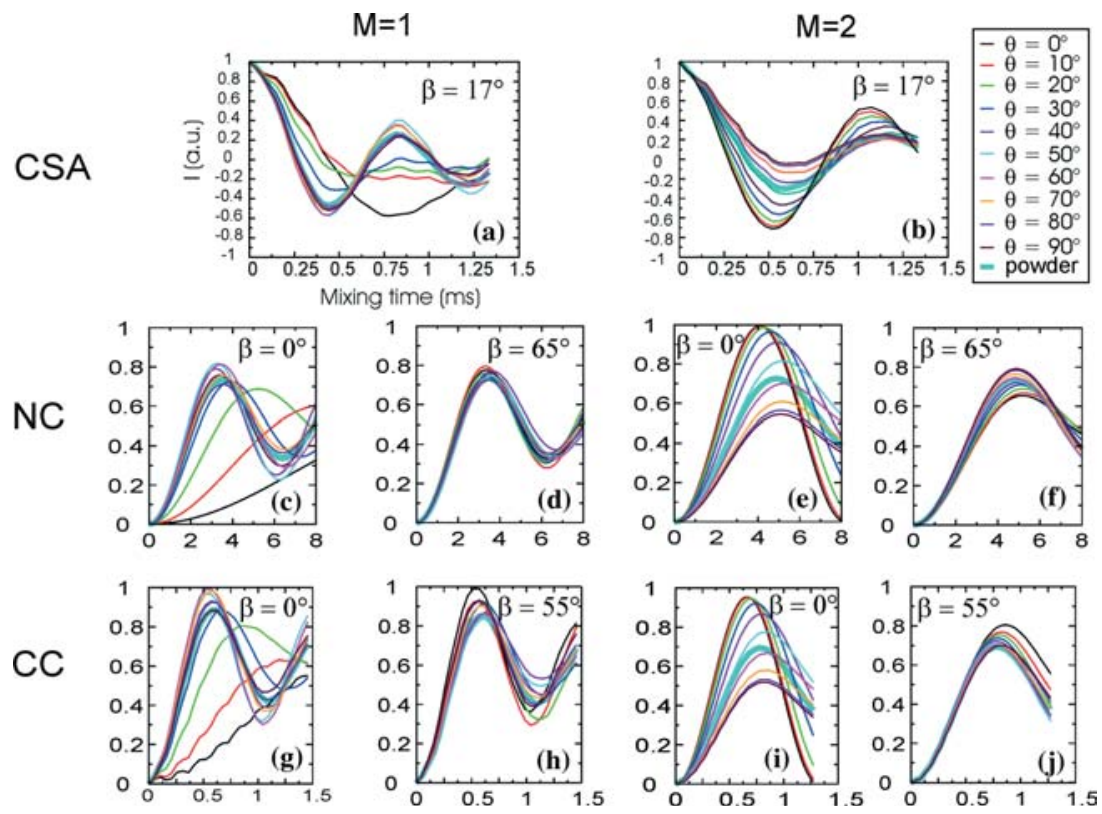

Figure 3. Numerical simulations for recoupling of the $M=1$ and $M=2$ space components of CSA and dipolar (NC or CC) interactions as a function of the tilt angle $\theta$. In $(\mathrm{a}, \mathrm{b})$ PAS values for the ${ }^{15} \mathrm{~N}$ CSA as given by Bechinger et al. (Sizun and Bechinger, 2002) were assumed using $\beta_{\mathrm{CSA}-\mathrm{N}}=17^{\circ}$ and the recoupling sequences $\mathrm{R} 18^{7}{ }_{1}(M=1)$ and $\mathrm{R} 18^{5}{ }_{2}(M=2)$. These computations were conducted assuming $6 \mathrm{kHz}$ MAS at $14.1 \mathrm{~T}\left(600 \mathrm{MHz}{ }^{1} \mathrm{H}\right.$ resonance frequency). (c-f): $\mathrm{N}-\mathrm{C} \alpha$ cross polarization buildups at $5 \mathrm{kHz}$ MAS using an $\mathrm{N}-\mathrm{C} \alpha$ distance of $1.45 \AA$ and $\beta_{\mathrm{D}-\mathrm{NC}}$ angles of $0^{\circ}(\mathrm{c}, \mathrm{e})$ and $65^{\circ}(\mathrm{d}, \mathrm{f})$. $(\mathrm{g}-\mathrm{j}) \mathrm{C} \alpha-\mathrm{C} \beta$ double quantum excitation using POST-C7 $(M=1, \mathrm{~g}, \mathrm{~h})$ and $\mathrm{C} 8^{3}{ }_{1}(M=2, \mathrm{i}, \mathrm{j})$ recoupling at $5.5 \mathrm{kHz}$ MAS. A C $\alpha-\mathrm{C} \beta$ distance of $1.5 \AA$ and $\beta_{\mathrm{D}-\mathrm{CC}}$ angles of $0^{\circ}(\mathrm{g}, \mathrm{h})$ and $55^{\circ}(\mathrm{i}, \mathrm{j})$ were assumed. In all simulations a spread $\Delta=8^{\circ}$ was incorporated. For the numerical simulations, one (CSA) or two (NC, CC) spin systems were considered and the signal intensity was averaged over 277 different orientations of $\varphi_{R}$ and 209 different values of $\varphi$ between $0^{\circ}$ and $360^{\circ}$ according to the method proposed by Cheng et al. (1973). For the calculation of the piecewise-constant Hamiltonian, the time increment was set to $0.55 \mu \mathrm{s}(5 \mathrm{kHz}$ MAS) and $0.46 \mu \mathrm{s}(6 \mathrm{kHz}$ MAS).

different orientations of the dipolar vectors $\mathrm{NC} \alpha$ and $\mathrm{C} \alpha \mathrm{C} \beta$ in the molecular frame (i.e., $\beta_{\mathrm{D}-}$ $\mathrm{NC}=0^{\circ}(\mathrm{c}, \mathrm{e}), \beta_{\mathrm{D}-\mathrm{NC}}=65^{\circ}(\mathrm{d}, \mathrm{f}), \beta_{\mathrm{D}-\mathrm{CC}}=0^{\circ}(\mathrm{g}, \mathrm{i})$ and $\left.\beta_{\mathrm{D}-\mathrm{CC}}=55^{\circ}(\mathrm{h}, \mathrm{j})\right)$ where non-zero values again correspond to angles typically found for an $\alpha$-helical geometry. The zero angles have been purposely chosen to illustrate the angular dependences given in Equations 5-7.

While we considered for CSA dephasing the recoupling sequences $\mathrm{R} 18^{7}{ }_{2}(M=1$, Figure 3a) and $\mathrm{R}_{1} 8_{2}^{5}(M=2$, Figure $3 \mathrm{~b})$, dipolar polarization transfer was established using $(\mathrm{N}, \mathrm{C})$ cross polarization (for $M=1$ and $M=2$ conditions) (Hartmann and Hahn, 1962; Pines et al., 1973; Baldus et al., 1996; Baldus et al., 1998) or DQ (C,C) POST-C7 ( $M=1$, Hohwy et al., 1998) or $\mathrm{C} 8^{3}{ }_{1}(M=2$, Levitt, 2002) schemes. Numerical predictions assuming a random (powder) orientation are included for reference (thick line). For the CSA case (MAS $=6 \mathrm{kHz}$ ), the signal modulation represents the dephasing of longitudinal magnetization. For $\mathrm{NC}$ and $\mathrm{CC}$ transfer, the buildup of single-quantum (1Q) $\left({ }^{13} \mathrm{C}_{\alpha}\right)$ or doublequantum (2Q) $\left({ }^{13} \mathrm{C}_{\alpha},{ }^{13} \mathrm{C}_{\beta}\right)$ coherence, respectively, is monitored. Numerical results for $\mathrm{N}-\mathrm{C} \alpha$ $(\mathrm{c}-\mathrm{f}, \mathrm{MAS}=5 \mathrm{kHz})$ and double quantum $\mathrm{C} \alpha-$ $\mathrm{C} \beta$ dipolar recoupling $(\mathrm{g}-\mathrm{j}, \mathrm{MAS}=5.5 \mathrm{kHz})$ are shown. Standard one-bond distances have been considered for the $\mathrm{N}-\mathrm{C} \alpha(1.45 \AA)$ and $\mathrm{C} \alpha-\mathrm{C} \beta$ $(1.5 \AA)$ dipolar couplings. In all simulations a Gaussian mosaic spread of $\Delta=8^{\circ}$ for the angle $\theta$ was assumed.

For all considered schemes, recoupling of the $M=1$ components leads to a limited sensitivity of the signal modulation to the molecular tilt angle $\theta$. In contrast, $M=2$ CSA dephasing exhibits a monotonic dependence on the molecular orientation for $\theta \in\left[0^{\circ}, 90^{\circ}\right]$ (Figure 3b). A more detailed analysis is presented in Figure 4, where the ${ }^{15} \mathrm{~N}$ CSA dephasing behavior at the minimum intensity (i.e., a dephasing time of $0.55 \mathrm{~ms}$ at $M=2$, Figure $3 \mathrm{~b}$ ) is displayed as 


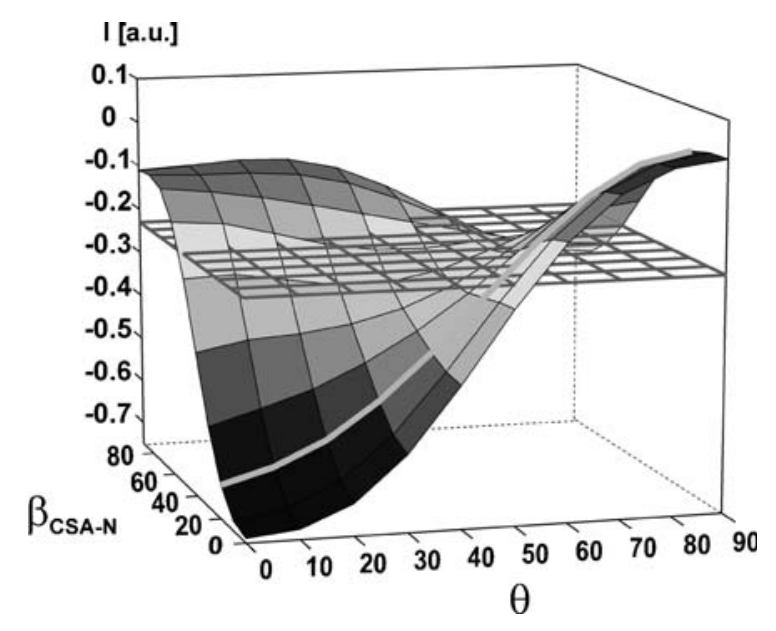

Figure 4. Signal modulation at the first minimum of the CSA dephasing curve (Figure $3 \mathrm{~b}, \mathrm{t}_{\mathrm{CSA}-\mathrm{N}}=0.55 \mathrm{~ms}$ ) as a function of $\theta$ and $\beta_{\text {CSA-N. }}$. For comparison, a plane reflecting the case of a randomly oriented powder sample is included. The case of an $\alpha$-helix is highlighted.

a function of the Euler angles $\theta$ and $\beta_{\mathrm{CSA}-\mathrm{N}}$ extending our analysis beyond the $\alpha$-helix case treated in Figure 3. For reference, results of a powder simulation are included as a plane. In agreement with Figure 3, the signal intensity is very sensitive to the molecular orientation for the case of an $\alpha$-helix. Interestingly, the dephasing signal at the considered mixing time vanishes for an in-plane orientation of the helix and becomes strongly negative for a trans-membrane orientation. The strongest variation for the case of an $\alpha$-helix is observed for tilt angles between $20^{\circ}$ and $70^{\circ}$.

Dipolar NC or CC recoupling at the $M=1$ condition, only leads to a significant dependence of the signal buildup upon the peptide orientation for the degenerate cases $\left(\beta_{\mathrm{D}-\mathrm{NC} / \mathrm{D}-\mathrm{CC}}=0^{\circ}\right.$, Figure $3 \mathrm{c}, \mathrm{g})$ and in the range $\theta \in\left[0^{\circ}, 30^{\circ}\right]$. Numerical simulations also permit to estimate the influence of the azimuthal angle $\varphi$. In Figure 5, simulations assuming the CSA dephasing time of Figure 4 and PAS values and orientation of an $\alpha$ helix are shown for variable $\varphi$ and helix tilt angle $\theta$. As expected, the signal intensities vary around the average (assuming cylindrical symmetry, indicated in bold) value. For the considered case of CSA dephasing (shown in Figure 5) but also for additional calculations referring to $\mathrm{NC}$ and $\mathrm{CC}$ transfer (data not shown), deviations are most significant for helix tilt angles larger than $10^{\circ}$ and

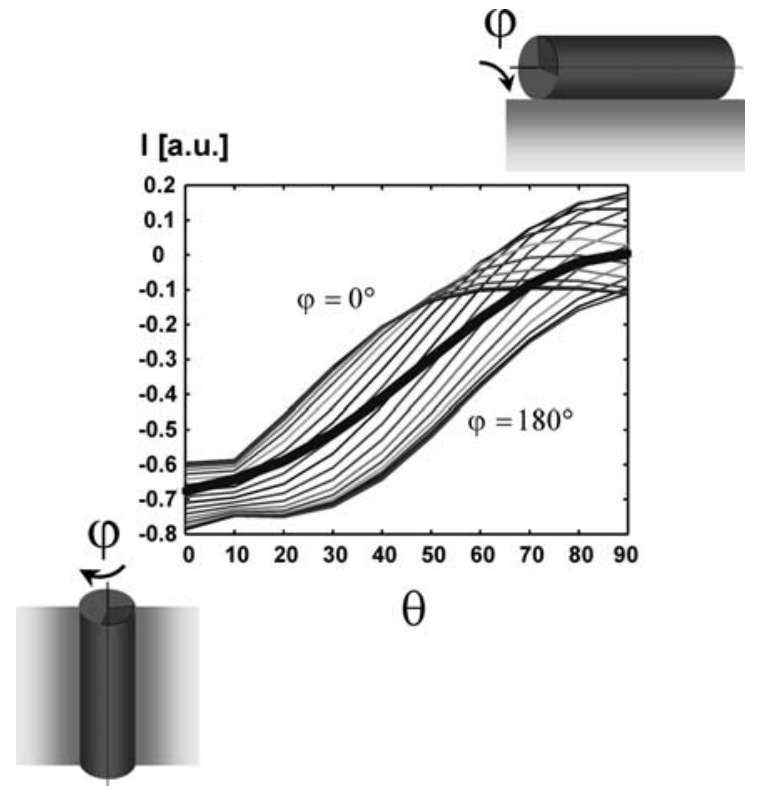

Figure 5. Dependence of the simulated signal intensity for a CSA dephasing time of $0.55 \mathrm{~ms}$ (Figure $3 \mathrm{~b}$ ) as a function of the molecular tilt angle $\theta$. Unlike in Figure $3 b$, numerical results are shown for specific values of the azimuthal angle $\varphi$ in the range of $0^{\circ}-180^{\circ}$ (in steps of $10^{\circ}$ ) and compared to the case of cylindrical symmetry (i.e., numerical integration over all possible $\varphi$ values, bold line).

will be neglected for the analysis of the experimental data presented in the following (also more reasons are given in the experimental section).

The results of Figures 3 and 4 suggest a possible combination of a CSA dephasing and dipolar transfer units in which only one of the transfer units, namely the CSA dephasing block, is sensitive to the peptide orientation and where the dipolar transfer dynamics are (for a general case of $\beta_{\mathrm{D}-\mathrm{NC} / \mathrm{CC}}>10^{\circ}$ ) largely insensitive to the overall molecular orientation in the membrane: Such a behavior should be expected if one combines a CSA $(\mathrm{M}=2)$ dephasing unit with dipolar $(\mathrm{M}=1)(\mathrm{N}, \mathrm{C})$ and $(\mathrm{C}, \mathrm{C})$ transfer schemes. In the following, we will exemplify such a generalized scheme for the case of unoriented tri-peptide and two membrane-embedded model peptides.

\section{Comparison to experimental results}

First, we investigated the accuracy with which CSA signal dephasing can be monitored in a constant-time experiment (Figure 1a) on a randomly oriented system. In Figure 6a, the CSA ${ }^{15} \mathrm{~N}$ 

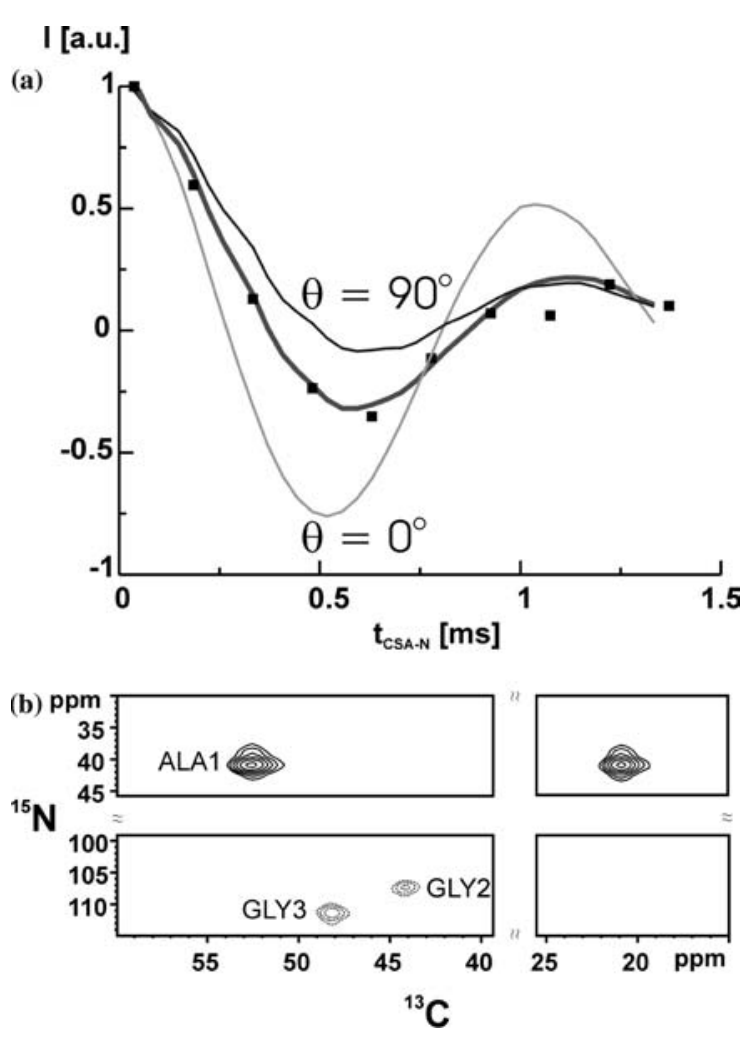

Figure 6. Experimental results of a powder sample of U- $\left[{ }^{13} \mathrm{C},{ }^{15} \mathrm{~N}\right]$ labelled AGG: (a) Comparison between experimental ${ }^{15} \mathrm{~N}$ CSA dephasing using $\mathrm{R} 18^{5}{ }_{2}(6 \mathrm{kHz}$ MAS, $600 \mathrm{MHz}{ }^{1} \mathrm{H}$ magnetic field) to simulations (solid line) assuming CSA values according to Oas et al. (1987) and a monoexponential relaxation time of $2 \mathrm{~ms}$ for the Gly 3 residue. For comparison, numerical results for a trans membrane $\left(\theta=0^{\circ}\right)$ and an in plane oriented peptide $\left(\theta=90^{\circ}\right)$ are included. (b) $2 \mathrm{D}$ ${ }^{15} \mathrm{~N} /{ }^{13} \mathrm{C}$ correlation experiment using the pulse sequence from Figure $1 \mathrm{~b}$ for $\mathrm{R} 18^{5}{ }_{2} \mathrm{CSA}$ dephasing for $0.55 \mathrm{~ms}$, NC $=$ SPECIFIC $\mathrm{CP}$ and $\mathrm{CC}=\mathrm{SD}$, (i.e., a spin diffusion transfer block (Bloembergen, 1949)). $64 \mathrm{t}_{1}$ increments with 128 scans were recorded using a $\mathrm{NC}$ transfer time of $4 \mathrm{~ms}$ and an SD mixing time of $5 \mathrm{~ms}$. Negative signal intensities (GLY 2/3) are indicated by dashed contour lines.

dephasing $(M=2)$ curve is shown for Gly3 residue of the $\mathrm{U}-\left[{ }^{13} \mathrm{C},{ }^{15} \mathrm{~N}\right]$ labeled tripeptide AlaGly-Gly. Numerical simulations using an overall relaxation time of $2 \mathrm{~ms}$ and ${ }^{15} \mathrm{~N}$ CSA tensor values previously obtained for AcGlyGlyNH $\mathrm{N}_{2}$ (Oas et al., 1987) are included for reference. The agreement between simulation and experiment is good and, as indicated by the thin reference lines, significantly differs from predictions assuming an uniaxially oriented peptide in a planar or transmembrane arrangement. In addition, Figure $6 \mathrm{~b}$ demonstrates the application of the 2D approach to encode anisotropic ${ }^{15} \mathrm{~N}$ CSA dephasing in a standard 2D NC correlation experiment. Again we consider as a control a uniformly labeled powder sample of AGG. The CSA R $18^{5}{ }_{2}$ dephasing time was set to $0.55 \mathrm{~ms}$ giving rise of negative signal ${ }^{15} \mathrm{~N}$ modulations (dashed contour levels) for all $\mathrm{NH}$ groups that are characterized by sizable ${ }^{15} \mathrm{~N}$ CSA tensor values. On the other hand, ${ }^{15} \mathrm{~N}$ nuclei such as the $\mathrm{NH}_{3}$ group of the $\mathrm{C}$ terminus where motional averaging leads to a strong reduction of the $\delta_{\mathrm{CSA}-\mathrm{N}}$ is only weakly affected by the dephasing block and hence occurs with positive signal intensity in the $2 \mathrm{D}$ spectrum of Figure $6 \mathrm{~b}$. After $\mathrm{NC}$ and $\mathrm{CC}$ transfer, these signal modulations are encoded on both $\mathrm{C}_{\alpha}$ and $\mathrm{C}_{\beta}$ chemical shifts, as visible in Figure 6b. For a zero-quantum (0Q) $\left({ }^{13} \mathrm{C},{ }^{13} \mathrm{C}\right)$ transfer, such as the spin diffusion transfer block (Bloembergen, 1949) utilized in Figure 6b, $C \alpha$ and $C \beta$ resonances are characterized by the same sign of the $2 \mathrm{D}$ signal amplitude (vide infra).

Next, a $1 \mathrm{D}{ }^{15} \mathrm{~N}$ CSA dephasing experiment was conducted on an oriented sample U$\left[{ }^{13} \mathrm{C},{ }^{15} \mathrm{~N}\right]$ Ala3-Gramicidin $\mathrm{A}$ using the $\mathrm{R} 18^{7}{ }_{1}$ scheme (Figure 7a, MAS $=5 \mathrm{kHz}$ ). Because Gramicidin A has been shown to adopt a head to head dimer structure in DMPC bilayers, the ${ }^{15} \mathrm{~N}$ signals of both monomer units are identical in frequency units and, for reasons of molecular symmetry, lead to analogous signal modulations in Figure 7a. For the numerical simulations included in Figure 7a, CSA tensor values as reported by Cross et al. (Mai et al., 1993) were used. Assuming the same relaxation time as in Figure 6a, good agreement between experimental results and numerical data is obtained assuming a trans-membrane orientation of the peptide. In the case of Ala3 of Gramicidin A, Cross et al. previously reported (Mai et al., 1993) that the ${ }^{15} \mathrm{~N}-{ }^{1} \mathrm{H}$ dipolar vector is oriented $20^{\circ}$ away from the $\beta$-helix axis, while the ${ }^{15} \mathrm{NH}$ CSA PAS $\sigma_{\mathrm{zz}}$ axis is tilted by $20^{\circ}$ with respect to the ${ }^{15} \mathrm{~N}-{ }^{1} \mathrm{H}$ bond. Hence, $\beta_{\mathrm{CSA}-\mathrm{N}}$ as given in Figure 2 can vary in the range of $0^{\circ}$ to $40^{\circ}$. Indeed, a numerical grid search using $\beta_{\mathrm{CSA}-\mathrm{N}} \in\left[0^{\circ}, 40^{\circ}\right]$ and $\theta \in\left[0^{\circ}\right.$, $\left.90^{\circ}\right]$ lead to the best fit to the experimental data for the pair $\beta_{\mathrm{CSA}-\mathrm{N}}=40^{\circ}$ and $\theta=0^{\circ}$.

Good agreement between numerical results and the NMR experiment is also observed for $\mathrm{U}-\left[{ }^{13} \mathrm{C},{ }^{15} \mathrm{~N}\right]$ Leu6Ala7 labeled WALP23 sample using an MAS rate of $6 \mathrm{kHz}$ and the $\mathrm{R} 18^{5}{ }_{2}$ scheme for CSA dephasing (Figure 7c). Notably, 

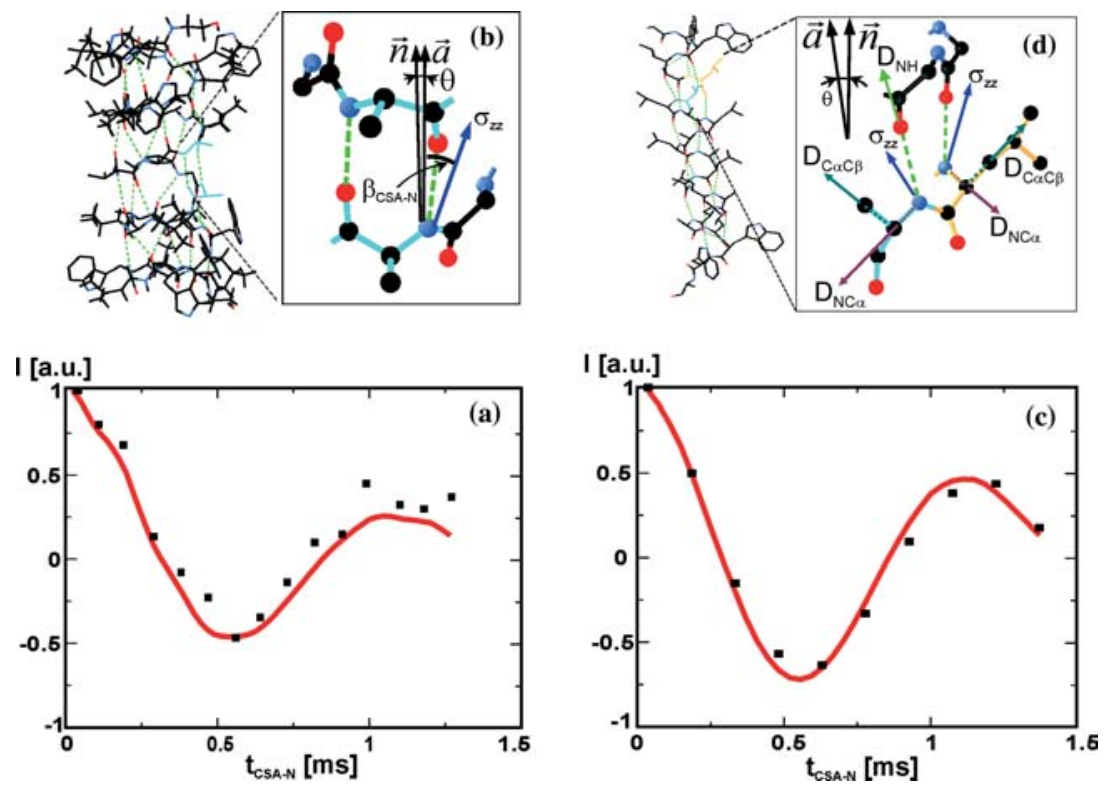

Figure 7. (a) ${ }^{15} \mathrm{~N}$ CSA recoupling of the $\left.\mathrm{U}^{13} \mathrm{C},{ }^{15} \mathrm{~N}\right]$ - Ala3 labeled Gramicidin A in DMPC oriented lipid bilayers (1/8 molar ratio) using the $\mathrm{R} 18^{7}{ }_{1}$ sequence at $5 \mathrm{kHz}$ MAS and $T=-15{ }^{\circ} \mathrm{C}$. For each of the 15 dephasing values (increment time $88 \mu \mathrm{s}-4(\pi \bar{\pi})$ pulses), 1536 scans were averaged at $600 \mathrm{MHz}\left({ }^{1} \mathrm{H}\right.$ resonance frequency). Simulations (solid line) were performed using ${ }^{15} \mathrm{~N}$ CSA values reported by Cross et al. (Mai et al., 1993). (b) The $\beta$-helix structure (Ketchem et al., 1993) of Gramicidin A in the lipid bilayer with a close-up around one of the two Ala3 residues and the relevant interactions. (c) Experimental results of a ${ }^{15} \mathrm{~N}$ CSA dephasing experiment on an $\left.\mathrm{U}^{13} \mathrm{C},{ }^{15} \mathrm{~N}\right]$ - Leu6, Ala7 doubly labeled WALP23 in DMPC oriented bilayers (1/16 molar ratio) using the R $18^{5}{ }_{2}$ sequence ( $6 \mathrm{kHz}$ MAS, $T=-15^{\circ} \mathrm{C}, 600 \mathrm{MHz}{ }^{1} \mathrm{H}$ magnetic field, $1 \mathrm{k}$ scans, 10 dephasing values). For comparison, simulations (solid line) assuming ${ }^{15} \mathrm{~N}$ CSA values as given in Sizun and Bechinger (2002) are included. A ${ }^{31} \mathrm{P}$-NMR spinning sideband analysis suggests a mosaic spread of $8^{\circ}$. Furthermore, the relaxation time observed for AGG was assumed. (d) The $\alpha$-helical structure of WALP23 in lipid bilayer generated within Insight II (Biosym Technologies, CA) focusing on the Leu6-Ala7 moiety and the relevant interactions.

the signal modulation is significantly more pronounced than in the powder sample of AGG or in the case of Gramicidin A. Assuming an $\alpha$-helix, the experimental data are best described if $\theta=5^{\circ}$, a value that is very close to results obtained using samples macroscopically oriented on glass plates (Strandberg et al., submitted). In addition, the GALA approach (van der Wel et al., 2002; Strandberg et al., submitted) using deuterated alanine residues in oriented bilayers leads to a helix tilt angle of $5.5^{\circ}$ of WALP23 in DMPC. Within the resolution of our experiments (see also Figure 5), both values are in good agreement with the data obtained under MAS.

In the case of doubly labeled WALP23 peptide, a $1 \mathrm{D}{ }^{15} \mathrm{~N}$ CSA dephasing experiment is not sufficient to probe individual residues. A $(\mathrm{C}, \mathrm{C})$ (DQ,SQ) (see, for example, Bax et al., 1980 and Baldus, 2002) correlation experiment shown in Figure 8a firmly establishes, in conjunction with standard chemical shift values, the spectral assign- ments of the two involved side chains. In Figures $8 \mathrm{~b}$ and $\mathrm{c}$, the corresponding $\mathrm{C} \alpha-\mathrm{C} \beta$ buildup characteristics were recorded for (b) an oriented version of WALP23 and (c) of WALP23 reconstituted in randomly oriented liposomes. For comparison, numerical results for both experimental setups are included. In line with our theoretical analysis and Figure 3 , the $\left({ }^{13} \mathrm{C},{ }^{13} \mathrm{C}\right)$ transfer mechanism is - within the limits of the experimental sensitivity - identical for both preparations and indicates that the transfer dynamics are not sensitive to the macroscopic sample orientation.

In Figure 9, we demonstrate the use of ${ }^{13} \mathrm{C}$ encoded ${ }^{15} \mathrm{~N}$ CSA dephasing experiment whenever ${ }^{13} \mathrm{C}$ resonance assignments (as obtained from Figure 8a) are available and an additional ${ }^{15} \mathrm{~N}$ evolution dimension is not necessary or precluded by signal to noise considerations. In the case of Ala-Leu isotope labeled WALP23, two 1D experiments for a CSA dephasing of $0 \mathrm{~ms}$ (a) and $0.55 \mathrm{~ms}$ (b) are shown. In both cases, the 

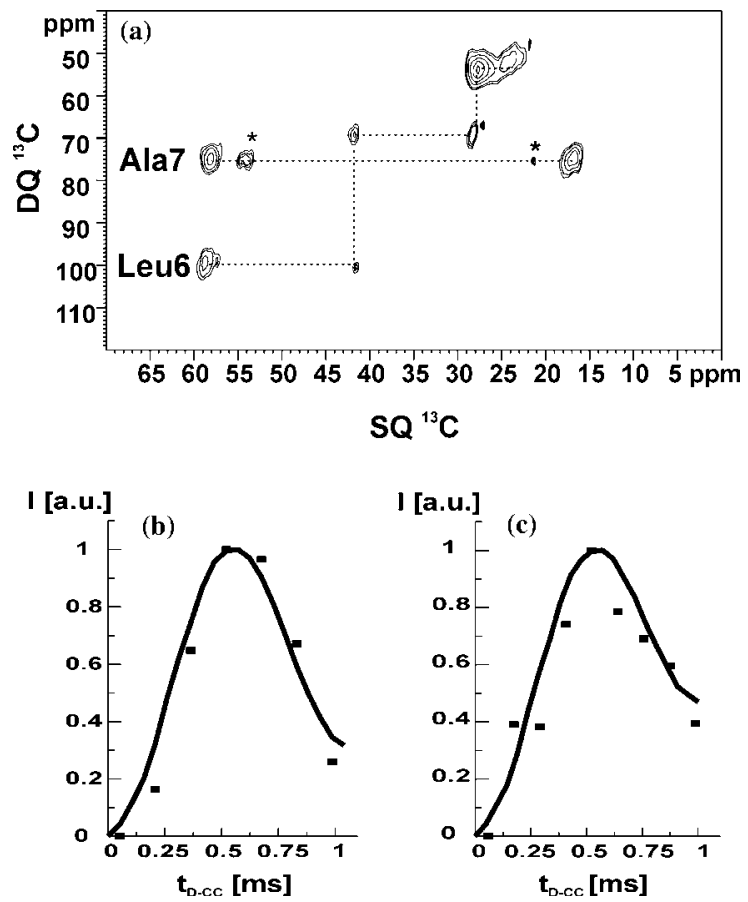

Figure $8:{ }^{13} \mathrm{C}$ solid-state NMR spectroscopy of WALP23 in oriented DMPC lipid bilayers: (a) $2 \mathrm{D}{ }^{13} \mathrm{C} \mathrm{DQ} / \mathrm{SQ}$ spectrum acquired with POST-C7, $5.5 \mathrm{kHz}$ MAS and $\mathrm{T}=-15^{\circ} \mathrm{C}$. Correlations in the side chain region can be assigned to Leu6 $\left(\mathrm{C} \alpha=58.6 \mathrm{ppm}, \mathrm{C} \beta=41.8 \mathrm{ppm}, \mathrm{C} \gamma=28.1 \mathrm{ppm}, \mathrm{C} \delta_{1,2}=\right.$ $24.8 \mathrm{ppm})$ and Ala7 residues $(\mathrm{C} \alpha=58.03 \mathrm{ppm}, \mathrm{C} \beta=$ $17.2 \mathrm{ppm})$. Asterisks indicating spinning sidebands are included. 2Q excitation and reconversion times were set to $0.6 \mathrm{~ms}$. $48 \mathrm{t}_{1}$ increments with 512 scans were recorded. (b) Comparison between the experimental ${ }^{13} \mathrm{C}$ DQ buildup of oriented WALP23 with POST-C7 $\left(5.5 \mathrm{kHz}\right.$ MAS, T $=-15^{\circ} \mathrm{C}, \mathrm{C} \beta$ peak of Ala7 is shown) and numerical predictions (solid line) assuming a $\mathrm{C} \alpha$ $\mathrm{C} \beta$ distance of $1.5 \AA, \beta_{\mathrm{D}-\mathrm{CC}}=55^{\circ}$ and a Gaussian spread $\Delta$ of $8^{\circ}$, (c) Experimentally detected ${ }^{13} \mathrm{C}$ DQ buildup of a WALP23 in randomly oriented liposomes with the same experimental setup. Numerical simulations are included as solid lines.

application of a SPC5 (Hohwy et al., 1999) double-quantum block leads to antiphase $\mathrm{C} \beta$ resonances (Baldus et al., 1994b). The relative ratio of $\mathrm{C} \beta$ signals at both mixing times allows for an estimate of the ${ }^{15} \mathrm{~N}$ signal modulation individually for both residues, leading to tilt angles similar to values obtained previously (van der Wel et al., 2002; Strandberg et al., submitted). The numerical analysis presented above suggests that the polypeptide orientation in the membrane can be determined with an accuracy of $\pm 10^{\circ}$ throughout the entire range of $\theta=\left[0^{\circ}, 90^{\circ}\right]$. The precision could further be improved by a combined analysis of several residues in a multiply-labeled peptide or

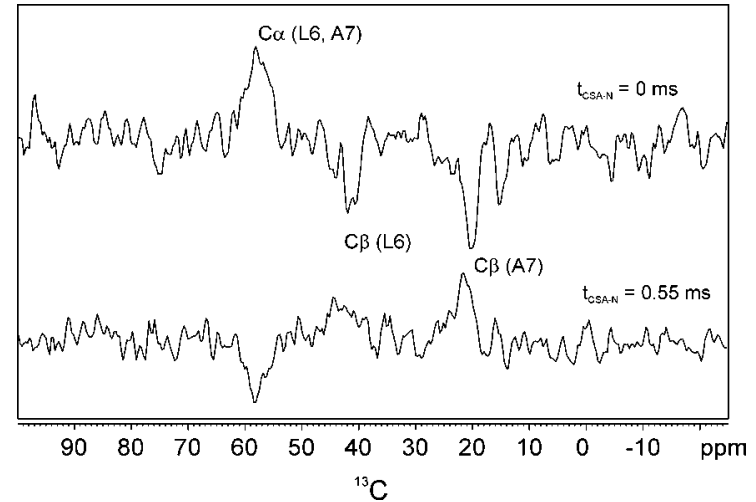

Figure $9 .{ }^{13} \mathrm{C}$ side chain resonances of WALP23 oriented in DMPC lipid bilayers detected after two different ${ }^{15} \mathrm{~N}$ CSA dephasing times (Figure $1 \mathrm{~b}: \mathrm{t}_{1}=0, \mathrm{CSA}=\mathrm{R} 18^{5}{ }_{2}, \mathrm{CC}=\mathrm{SPC} 5$, $6 \mathrm{kHz}$ MAS, $48 \mathrm{k}$ scans): (a) $0 \mathrm{~ms}{ }^{15} \mathrm{~N}$ CSA recoupling and (b) $0.55 \mathrm{~ms}{ }^{15} \mathrm{~N}$ CSA recoupling. SPECIFIC CP and SPC5 recoupling were applied for $4 \mathrm{~ms}$ and $0.8 \mathrm{~ms}$, respectively. Assignments were obtained from Figure 8.

by incorporating structural constraints obtained from an analysis of the dipolar $\mathrm{NH}$ interactions. The same approach also permits restriction of the number of possible angular solutions in cases where a cylindrical symmetry around $\varphi$ cannot be assumed (see Figure 5).

In the presented examples, the anisotropic orientation of the molecule was encoded as an additional amplitude modulation. Unlike in the case of a membrane peptide oriented on static glass plates, the resonance frequencies can here be used to independently probe local backbone conformation. As demonstrated for a series of uniformly labeled polypeptides (Luca et al., 2001), the relevant chemical shift assignments only must be related to the average (random coil) chemical shifts. For WALP23, these values are readily available from solution-state NMR studies and lead to secondary chemical shifts $\Delta \delta$ that are consistent with an $\alpha$-helical backbone conformation for both considered residues. A subsequent structural analysis using TALOS leads to the backbone angles $\left(\phi=-66.85^{\circ} \pm\right.$ $\left.6.79^{\circ}, \psi=-41.24^{\circ} \pm 8.63^{\circ}\right)$ and $\left(\phi=-68.80^{\circ} \pm\right.$ $15.37^{\circ}, \psi=-18.26^{\circ} \pm 31.67^{\circ}$ ) in line with the predicted $\alpha$-helical arrangement of the model peptide. A similar approach is not possible for Gramicidin A due to the occurrence of both D and $\mathrm{L}$ residue types. 


\section{Conclusions}

The structural characterization of membrane proteins is of considerable importance in a variety of biological processes. Unlike X-ray crystallography and solution-state NMR, biophysical investigations using solid-state NMR can be conducted in non-crystalline or insoluble environment. Such studies however often require appropriate sensitivity and spectral resolution. We have introduced a general approach to probe membrane protein structure under fast magic angle spinning. The presented methods simultaneously yield structural constraints for the local backbone conformation and the overall orientation of the polypeptide interacting with a model membrane environment. Notably, both structural parameters can be probed separately within the same NMR scheme. Moreover, the NMR methods can be readily extended to spectral assignment methods or techniques that measure nontrivial structural constraints under standard MAS conditions from $\left({ }^{1} \mathrm{H},{ }^{1} \mathrm{H}\right)$ transfer steps (Lange et al., 2002; Bockmann et al., 2003), from monitoring the dephasing of multiple-quantum coherence or by determining internuclear distances using chemical shift-selective transfer methods (Takegoshi et al., 1995; Costa et al., 1997; Sonnenberg et al., 2004).

The accuracy with which the molecular orientation can be detected depends on experimental parameters such as overall sensitivity and the molecular symmetry. Similar to experiments that rely on the structural analysis of ${ }^{15} \mathrm{~N}$ resonance shifts in static aligned samples (Marassi and Opella, 2000; Wang et al., 2000; Mesleh et al., 2003), the data interpretation must in general include mosaic spread effects and is less accurate than the GALA approach using a series of ${ }^{2} \mathrm{H}$ labeled peptides (van der Wel et al., 2002). On the other hand, the discussed concept permits structural studies using a single NMR sample and can be probed in a standard MAS setup. In addition, the accuracy can be improved by a combined analysis of several residues in a multiply-labeled peptide. Using the alignment technique proposed by Bechinger et al. (Sizun and Bechinger, 2002), oriented samples can be readily prepared and the functional dependence of the NMR data resulting from the proposed r.f. schemes is particularly sensitive to molecular orientations at or close to the membrane normal, a situation most likely to occur for transmembrane segments of ion channels, transporters or G-protein coupled receptors.

\section{Acknowledgements}

Discussions with Prof C. Griesinger, Prof T. Salditt (Univ. of Goettingen) and Dr C.E. Hughes are gratefully acknowledged. O.C.A. thanks Dr L. Verdier for help with the construction and analysis of the 3D model of WALP23 in INSIGHTII. This research project has been funded in part by the Volkswagen foundation.

Supporting Information Available at: http// kluweronline.com/issn/0925-2738

\section{References}

Andrew, E.R., Bradbury, A. and Eades, R.G (1958) Nature, 182, 1659.

Arndt, H.D., Vescovi, A., Schrey, A., Pfeifer, J.R. and Koert, U. (2002) Tetrahedron, 58, 2789-2801.

Auge, S., Mazarguil, H., Tropis, M. and Milon, A. (1997) J. Magn. Reson., 124, 455-458.

Baldus, M. (2002) Prog. NMR Spectrosc., 41, 1-47.

Baldus, M., Geurts, D.G., Hediger, S. and Meier, B.H. (1996) J. Magn. Reson., A118, 140-144.

Baldus, M., Levante, T.O. and Meier, B.H. (1994a) Z. Naturforsch. Section a-a, J. Phys. Sci., 49, 80-88.

Baldus, M., Tomaselli, M., Meier, B.H. and Ernst, R.R. (1994b) Chem. Phys. Lett., 230, 329-336.

Baldus, M., Petkova, A.T., Herzfeld, J. and Griffin, R.G. (1998) Mol. Phys., 95, 1197-1207.

Bax, A., Freeman, R. and Kempsell, S.P. (1980) J. Am. Chem. Soc., 102, 4849-4851.

Bechinger, B., Kinder, R., Helmle, M., Vogt, T.C.B., Harzer, U. and Schinzel, S. (1999) Biopolymers, 51, 174 190.

Bennett, A.E., Rienstra, C.M., Auger, M., Lakshmi, K.V. and Griffin, R.G. (1995) J. Chem. Phys., 103, 6951-6958.

Bloembergen, N. (1949) Physica, 15, 386-426.

Bockmann, A., Lange, A., Galinier, A., Luca, S., Giraud, N., Juy, M., Heise, H., Montserret, R., Penin, F. and Baldus, M. (2003) J. Biomol. NMR, 27, 323-339.

Bodner, M.L., Gabrys, C.M., Parkanzky, P.D., Yang, J., Duskin, C.A. and Weliky, D.P. (2004) Magn. Reson. Chem., 42, 187-194.

Brink, D.M. and Satchler, G.R. (1961) Angular Momentum, Oxford University Press.

Carravetta, M., Eden, M., Zhao, X., Brinkmann, A. and Levitt, M.H. (2000) Chem. Phys. Lett., 321, 205-215.

Cheng, V.B., Suzukawa, H.H. and Wolfsber, M. (1973) J. Chem. Phys., 59, 3992-3999.

Cornilescu, G., Delaglio, F. and Bax, A. (1999) J. Biomol. NMR, 13, 289-302. 
Costa, P.R., Sun, B.Q. and Griffin, R.G. (1997) J. Am. Chem. Soc., 119, 10821-10830.

Cross, T.A. and Opella, S.J. (1994) Curr. Opin. Struct. Biol., 4, 574-581.

Cross, T.A. and Quine, J.R. (2000) Concepts Magn. Reson., 12, 55-70.

Cross, T.A., Arseniev, A., Cornell, B.A., Davis, J.H., Killian, J.A., Koeppe, R.E., Nicholson, L.K., Separovic, F. and Wallace, B.A. (1999) Nat. Struct. Biol., 6, 610-611.

De Planque, M.R.R. and Killian, J.A. (2003) Mol. Membr. Biol., 20, 271-284.

de Planque, M.R.R., Boots, J.W.P., Rijkers, D.T.S., Liskamp, R.M.J., Greathouse, D.V. and Killian, J.A. (2002) Biochemistry, 41, 8396-8404.

Demura, M., Minami, M., Asakura, T. and Cross, T.A. (1998) J. Am. Chem. Soc., 120, 1300-1308.

Ernst, R.R., Bodenhausen, G. and Wokaun, A. (1987) Principles of Nuclear Magnetic Resonance in One and Two Dimensions, Clarendon Press.

Fu, R.Q., Cotten, M. and Cross, T.A. (2000) J. Biomol. NMR, 16, 261-268.

Gabrys, C.M., Yang, J. and Weliky, D.P. (2003) J. Biomol. $N M R$, 26, 49-68.

Glaubitz, C. and Watts, A. (1998) J. Magn. Reson., 130, 305-316.

Glaubitz, C., Burnett, I.J., Grobner, G., Mason, A.J. and Watts, A. (1999) J. Am. Chem. Soc., 121, 5787-5794.

Glaubitz, C., Grobner, G. and Watts, A. (2000) Biochim. Biophys. Acta, 1463, 151-161.

Glaubitz, C.C., M. Eden, M. Levitt, M.H. (2001) In Focus on Structural Biology, Vol. 1: Perspectives on Solid-State NMR in Biology, Kiihne, S., de Groot, H.J.M., Kluwer Academic Publishers, Dordrecht, pp 71-81.

Griffin, R.G. (1998) Nat. Struct. Biol., 5, 508-512.

Grobner, G., Burnett, I.J., Glaubitz, C., Choi, G., Mason, A.J. and Watts, A. (2000) Nature, 405, 810-813.

Haeberlen, U. (1976) In Advances in Magnetic Resonance, High Resolution NMR in Solids: Selective Averaging, Waugh, J. S., Academic Press.

Harbison, G.S. and Spiess, H.W. (1986) Chem. Phys. Lett., 124, 128-134.

Hartmann, S.R. and Hahn, E.L. (1962) Phys. Rev., 128, 2042-2053.

Herzfeld, J. and Berger, A.E. (1980) J. Chem. Phys., 73, 6021-6030.

Hirsh, D.J., Hammer, J., Maloy, W.L., Blazyk, J. and Schaefer, J. (1996) Biochemistry, 35, 12733-12741.

Hohwy, M., Jakobsen, H.J., Eden, M., Levitt, M.H. and Nielsen, N.C. (1998) J. Chem. Phys., 108, 2686-2694.

Hohwy, M., Rienstra, C.M., Jaroniec, C.P. and Griffin, R.G. (1999) J. Chem. Phys., 110, 7983-7992.

Hu, W., Lazo, N.D. and Cross, T.A. (1995) Biochemistry, 34, $14138-14146$

Hughes, C.E., Luca, S. and Baldus, M. (2004) Chem. Phys. Lett., 385, 435-440.

Ketchem, R.R., Hu, W. and Cross, T.A. (1993) Science, 261, 1457-1460.

Ketchem, R.R., Roux, B. and Cross, T.A. (1997) Structure, 5, 1655-1669.

Killian, J.A. (1992) Biochim. Biophys. Acta, 1113, 391-425.

Lange, A., Luca, S. and Baldus, M. (2002) J. Am. Chem. Soc., 124, 9704-9705.

Levante, T.O., Baldus, M., Meier, B.H. and Ernst, R.R. (1995) Mol. Phys., 86, 1195-1212.
Levitt, M.H. (2002) In Encyclopedia of Nuclear Magnetic Resonance: Supplementary Volume, Symmetry-Based Pulse Sequences in Magic-Angle Spinning Solid-State NMR, Harris, R. K., Wiley, 165-196.

Luca, S., Filippov, D.V., van Boom, J.H., Oschkinat, H., de Groot, H.J.M. and Baldus, M. (2001) J. Biomol. NMR, 20, 325-331.

Luca, S., Heise, H. and Baldus, M. (2003a) Acc. Chem. Res., 36, 858-865.

Luca, S., White, J.F., Sohal, A.K., Filippov, D.V., van Boom, J.H., Grisshammer, R. and Baldus, M. (2003b) Proc. Natl. Acad. Sci. USA, 100, 10706-10711.

Mai, W., Hu, W., Wang, C. and Cross, T.A. (1993) Protein Sci., 2, 532-542.

Marassi, F.M. (2002) Concepts Magn. Reson., 14, 212-224.

Marassi, F.M. and Opella, S.J. (1998) Curr. Opin. Struct. Biol., 8, 640-648.

Marassi, F.M. and Opella, S.J. (2000) J. Magn. Reson., 144, $150-155$.

McDowell, L.M. and Schaefer, J. (1996) Curr. Opin. Struct. Biol., 6, 624-629.

Mehring, M. (1983) Principles of High Resolution NMR in Solids, Springer.

Mesleh, M.F., Lee, S., Veglia, G., Thiriot, D.S., Marassi, F.M. and Opella, S.J. (2003) J. Am. Chem. Soc., 125, 8928-8935.

Oas, T.G., Hartzell, C.J., Dahlquist, F.W. and Drobny, G.P. (1987) J. Am. Chem. Soc., 109, 5962-5966.

Opella, S.J. and Waugh, J.S. (1977) J. Chem. Phys., 66, 4919-4924.

Pines, A., Gibby, M.G. and Waugh, J.S. (1973) J. Chem. Phys., 59, 569-590.

Salditt, T. (2003) Curr. Opin. Struct. Biol., 13, 467-478.

Sizun, C. and Bechinger, B. (2002) J. Am. Chem. Soc., 124, $1146-1147$.

Smith, S.A., Levante, T.O., Meier, B.H. and Ernst, R.R. (1994) J. Magn. Reson., A106, 75-105.

Smith, S.O., Aschheim, K. and Groesbeek, M. (1996) Q. Rev. Biophys., 29, 395-449.

Smith, S.O., Kawakami, T., Liu, W., Ziliox, M. and Aimoto, S. (2001a) J. Mol. Biol., 313, 1139-1148.

Smith, S.O., Song, D., Shekar, S., Groesbeek, M., Ziliox, M. and Aimoto, S. (2001b) Biochemistry, 40, 6553-6558.

Sonnenberg, L., Luca, S. and Baldus, M. (2004) J. Magn. Reson., 166, 100-110.

Strandberg, E., Morein, S., Rijkers, D.T.S., Liskamp, R.M.J., van der Wel, P.C.A. and Killian, J.A. (2002) Biochemistry, 41, 7190-7198.

Takegoshi, K., Nomura, K. and Terao, T. (1995) Chem. Phys. Lett., 232, 424-428.

Thompson, L.K. (2002) Curr. Opin. Struct. Biol., 12, 661-669.

Tian, F. and Cross, T.A. (1998) J. Magn. Reson., 135, 535-540.

van der Wel, P.C.A., Strandberg, E., Killian, J.A. and Koeppe, R.E. (2002) Biophys. J., 83, 1479-1488.

Wang, J., Denny, J., Tian, C., Kim, S., Mo, Y., Kovacs, F., Song, Z., Nishimura, K., Gan, Z., Fu, R., Quine, J.R. and Cross, T.A. (2000) J. Magn. Reson., 144, 162-167.

Yang, J. and Weliky, D.P. (2003) Biochemistry, 42, 11879 11890.

Zeri, A.C., Mesleh, M.F., Nevzorov, A.A. and Opella, S.J. (2003) Proc. Natl. Acad. Sci. USA, 100, 6458-6463.

Zhao, X., Eden, M. and Levitt, M.H. (2001) Chem. Phys. Lett., 342, 353-361. 